\title{
Ultrasensitive detection of explosives and chemical warfare agents by low-pressure photoionization mass spectrometry
}

\author{
Wanqi Sun, Miao Liang, Zhen Li, Jinian Shu*, Bo Yang, Ce Xu, Yao Zou \\ State Key Joint Laboratory of Environment Simulation and Pollution Control, Research Center for Eco-Environmental Sciences, Chinese Academy of Sciences, \\ Beijing 100085, China
}

\section{A R T I C L E I N F O}

\section{Article history:}

Received 26 February 2016

Received in revised form

3 May 2016

Accepted 9 May 2016

Available online 10 May 2016

Keywords:

Ultrasensitive detection

Low-pressure photoionization mass spec-

trometry

Explosive

Chemical warfare agent

\begin{abstract}
A B S T R A C T
On-spot monitoring of threat agents needs high sensitive instrument. In this study, a low-pressure photoionization mass spectrometer (LPPI-MS) was employed to detect trace amounts of vapor-phase explosives and chemical warfare agent mimetics under ambient conditions. Under 10-s detection time, the limits of detection of 2,4-dinitrotoluene, nitrotoluene, nitrobenzene, and dimethyl methyl phosphonate were $30,0.5,4$, and 1 parts per trillion by volume, respectively. As compared to those obtained previously with PI mass spectrometric techniques, an improvement of 3-4 orders of magnitude was achieved. This study indicates that LPPI-MS will open new opportunities for the sensitive detection of explosives and chemical warfare agents.
\end{abstract}

(c) 2016 Elsevier B.V. All rights reserved.

\section{Introduction}

The recent increase in international terrorist activities has highlighted the need for rapid, sensitive, and ideally real-time monitoring methods for threat agents, explosives, and chemical warfare agents (threat agents and related compounds are collectively referred to here as TAs) with minimal false positive results. Nitro-containing explosives, such as trinitrotoluene (TNT), are commonly used in explosive materials. The direct detection of such substances is a challenge due to their low vapor pressures [1]. 2,4-Dinitrotoluene (2,4-DNT), an impurity that is produced during the production of TNT, accounts for $35 \%$ of the vapor composition because of its much higher vapor pressure [2]. Thus, 2,4-DNT is suggested to be the best chemical signature for the vapor-phase detection of TNT [2-5]. Additionally, the degradation products of TNT, such as nitrotoluene (NT) and nitrobenzene (NB), also have higher vapor pressures, and thus could serve as suitable chemical signatures for such explosives [6]. On the other hand, chemical warfare agents such as sarin are extremely toxic, and small amounts are sufficient to cause serious injury or death [7]. As dimethyl methyl phosphonate (DMMP) is a nontoxic compound with a chemical structure similar to many chemical warfare agents, it is typically used as a mimetic for chemical warfare agents in the development of viable detectors.

\footnotetext{
* Corresponding author.

E-mail address: jshu@rcees.ac.cn (J. Shu).
}

Ion mobility spectrometry (IMS) is the most successful and widely used method for the on-spot trace detection of TAs [8,9]. Its limit of detection (LOD) is as low as 10 part per trillion by volume (pptv) [10]. Despite its sensitivity and robustness, IMS has limited chemical specificity, partly resulting from the low temporal resolution inherent in the separation of the ion mobility peaks, which can result in false positive results [11]. The use of a radiation-based ionization source, which is subject to safety and bureaucratic limitations, is another disadvantage [12]. Proton-transfer-reaction mass spectrometry (PTR-MS) has also been employed to detect trace quantities of TAs. Its LOD is similar to that of IMS; [13] however, it can provide higher selectivity than IMS, and thus yields greater confidence in compound assignments [14]. A limitation of PTR-MS is the need for a rapid cycle time for detection, that is, the entire process of sampling, analysis, and recovery (no memory effects) ideally needs to be complete within tens of seconds [15]. Additionally, military applications and some civilian applications including high-profile event security, emergency first responder protection, and hazardous material investigations require systems that can detect a host of target compounds at ultralow concentrations in real-time (1-10 s) [16]. Given the aforementioned limitations, the usefulness of PTR-MS in on-spot applications is restricted.

Developments in photoionization (PI) technologies [17-22] have indicated that PI mass spectrometry (PI-MS) could be a viable alternative to IMS or PTR-MS. PI is a traditional analytical method [19]. Previously, it was limited to high vacuum conditions, where 
nascent ions were free from collisions. The ions were generated via the reaction between photons and molecules solely. Based on the pressure in the PI region, traditional PI is known as vacuum PI. Vacuum PI has been used widely and several pioneering reports have illustrated its viability in the detection of TAs; however, the LOD of vacuum PI is only at the ten-ppbv level [6,18,22]. Atmospheric pressure PI (APPI) is a relatively new technique employed under ambient pressure, which mainly yields ions via electron attachments and molecule/ion reactions. The APPI source has been commercialized, and is usually coupled to liquid chromatography [23]. However, the direct measurement of TAs with this technique is rare. Low-pressure PI (LPPI) is a relatively new development in $\mathrm{PI}$, which is usually conducted under a pressure equal to hundreds of pascals. LPPI is based on aspects of vacuum PI and APPI. Molecular ions and protonated molecules were observed in LPPI mass spectra [24,25]. A previous study revealed that LPPI has an excellent sensitivity and have the ability to on-line monitoring trace amount volatile organic compounds in the atmosphere [26].

In order to explore the application of LPPI in trace TA detection, we investigated the detection of 2,4-DNT, NT, NB, and DMMP using a laboratory-built LPPI-mass spectrometer. The experimental method and results are reported in the following sections.

\section{Experimental section}

\subsection{Instrumentation}

Fig. 1 shows the experimental apparatus used in this study. The experimental setup mainly consisted of a $120-\mathrm{L}$ calibration chamber and an LPPI mass spectrometer.

The 120-L calibration chamber was comprised of an open-head stainless-steel drum and a thin Tedlar bag. Adequate mixing was ensured by using a magnetic stirring fan set at the bottom of the drum. Synthetic air ( $80 \%$ nitrogen $+20 \%$ oxygen) was used as the buffer gas for the sample sensitivity measurements and was prepared with two mass-flow meters. Ambient air was used as the buffer gas for obtaining the standard deviation of the noise $(\sigma)$ after filtering with a filter containing silica gel, molecular sieves, and activated carbon. An oil-free pump was used as the drain pump. All experiments were performed under ambient atmospheric pressure and room temperature.

The LPPI mass spectrometer was recently developed in our laboratory and has been described in detail elsewhere [26]. Briefly, it is composed of an LPPI source, an ambient sample inlet, and a short reflection time-of-flight mass spectrometer. The LPPI source consists of a $\mathrm{Kr}$ vacuum ultraviolet (VUV) lamp and a specially designed photoionizer with a cylindrical cavity (ionization zone) and an optical baffle. Ten-eV photons were generated by the $\mathrm{Kr}$ VUV lamp and the pressure in the LPPI source was $500-1000 \mathrm{~Pa}$. The sample flow was maintained at $\sim 1 \mathrm{~cm}^{3} \mathrm{~s}^{-1}$ without any preconcentration. The time-of-flight mass spectrometer was $\mathrm{V}$-shaped and had a flight distance of $460 \mathrm{~mm}$. The cycle time of detection was $10 \mathrm{~s}$.

\subsection{Sample preparation}

To simulate the vapor concentrations of explosives and chemical warfare agents, samples of NT, NB, and DMMP were prepared by two-step dilutions to obtain trace levels (ppbv/pptv). First, pure samples of NT, NB, and DMMP were diluted $6 \times 10^{5}$, $5.0 \times 10^{5}$, and $5.4 \times 10^{6}$ fold, respectively, with dichloromethane. Then, $10 \mu \mathrm{L}$ of the prepared solution was extracted with syringes and injected into the $120 \mathrm{~L}$-calibration chamber filled with synthetic air. The linear responses of the three compounds were obtained by gradually increasing their concentrations. Due to the low vapor pressure and high viscosity, 2,4-DNT could not be prepared by the dilution method abovementioned. A 6-L narrow-mouthed bottle sealed with a Teflon bag was employed. One layer of 2,4DNT was spread on the bottom of the bottle. Under ambient conditions, the gas in the bottle was directly detected after $48 \mathrm{~h}$.

In this study, NT (99.5\%), NB (99\%), DMMP (98\%), and 2,4-DNT (99.5\%) were purchased from J\&K Chemical Ltd., while dichloromethane (chromatography grade) was obtained from J. T. Baker Co. Ltd. High-purity nitrogen ( $>99.999 \%$ ) and oxygen ( $>$ 99.999\%) were purchased from Beijing Haikeyuanchang Practical Gas Co., Ltd. and Beijing Huayuan Gas Chemical Industry Co., Ltd., respectively.

\section{Results and discussion}

The LPPI mass spectrum of 2,4-DNT is shown in Fig. 2. The mass peak at $m / z 182$ corresponds to the molecular ion of 2,4-DNT (ionization energy, $\mathrm{IE}=10 \mathrm{eV}$ ). Under $10 \mathrm{eV}$ VUV radiation in the LPPI source, [26] the ionization of 2,4-DNT is reasonable. The mass peak at $\mathrm{m} / \mathrm{z} 183$ corresponds to protonated 2,4-DNT, which resulted from the interaction between the molecular ions and neutral species in matrix gases [24]. Mass peaks at $m / z=165,135$, and 119 were assigned to daughter ions of 2,4-DNT via loss of $\mathrm{OH}$, $(\mathrm{OH}+\mathrm{NO})$, and $\left(\mathrm{OH}+\mathrm{NO}_{2}\right)$ during LPPI. The daughter ion with 165 Th was the dominant mass peak of 2,4-DNT photoionized by VUV photons emitted from a krypton VUV lamp and was identified by MS/MS [20]. The formation of daughter ions with 135 and 119 Th

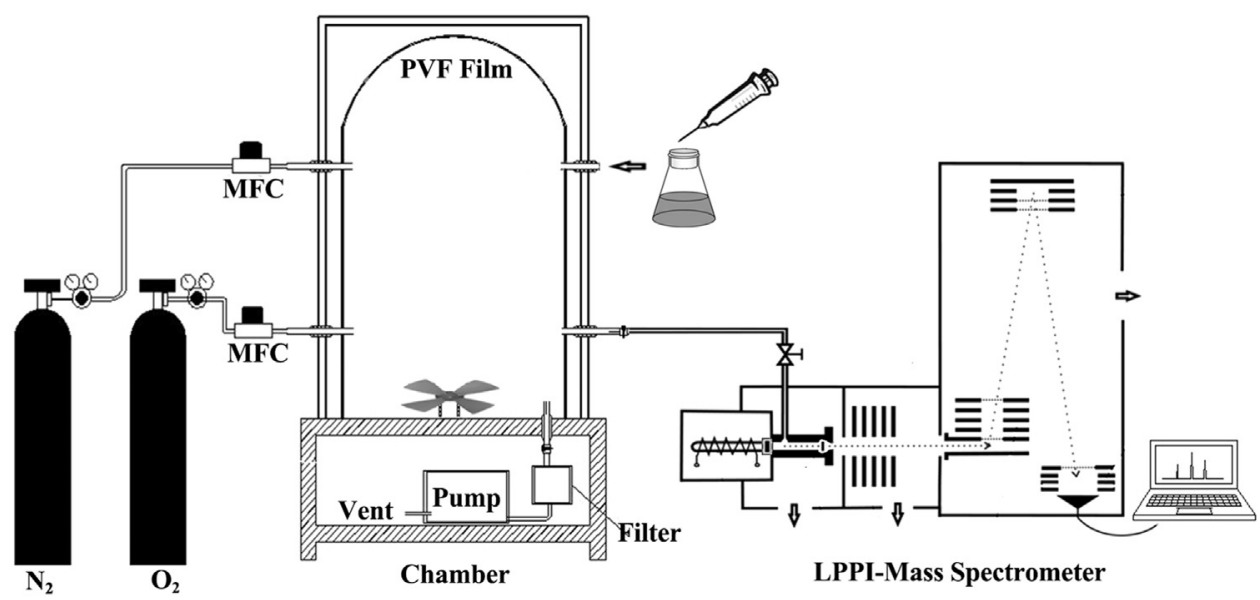

Fig. 1. Experimental setup. $M F C=$ mass flowmeter; $L P P I=$ low pressure photoionization; $P V F=$ polyvinyl fluoride. 


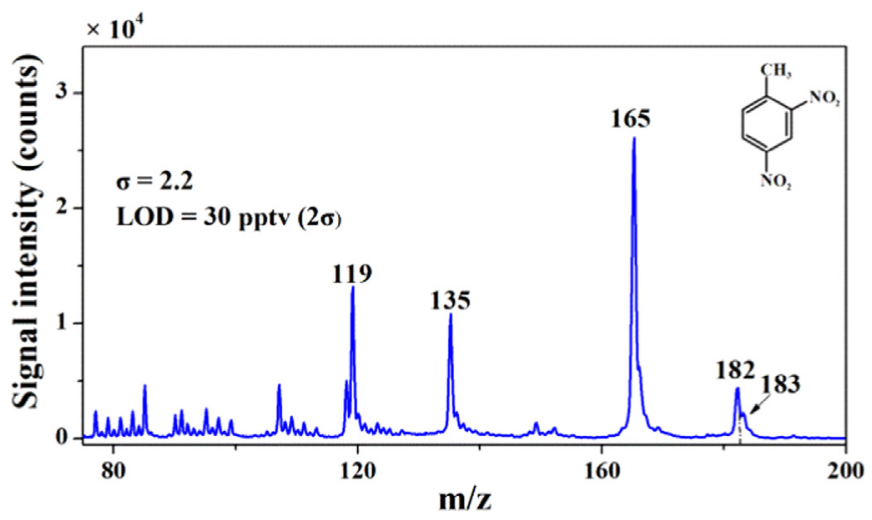

Fig. 2. Low-pressure photoionization mass spectrum of 2,4-Dinitrotoluene (2,4DNT).
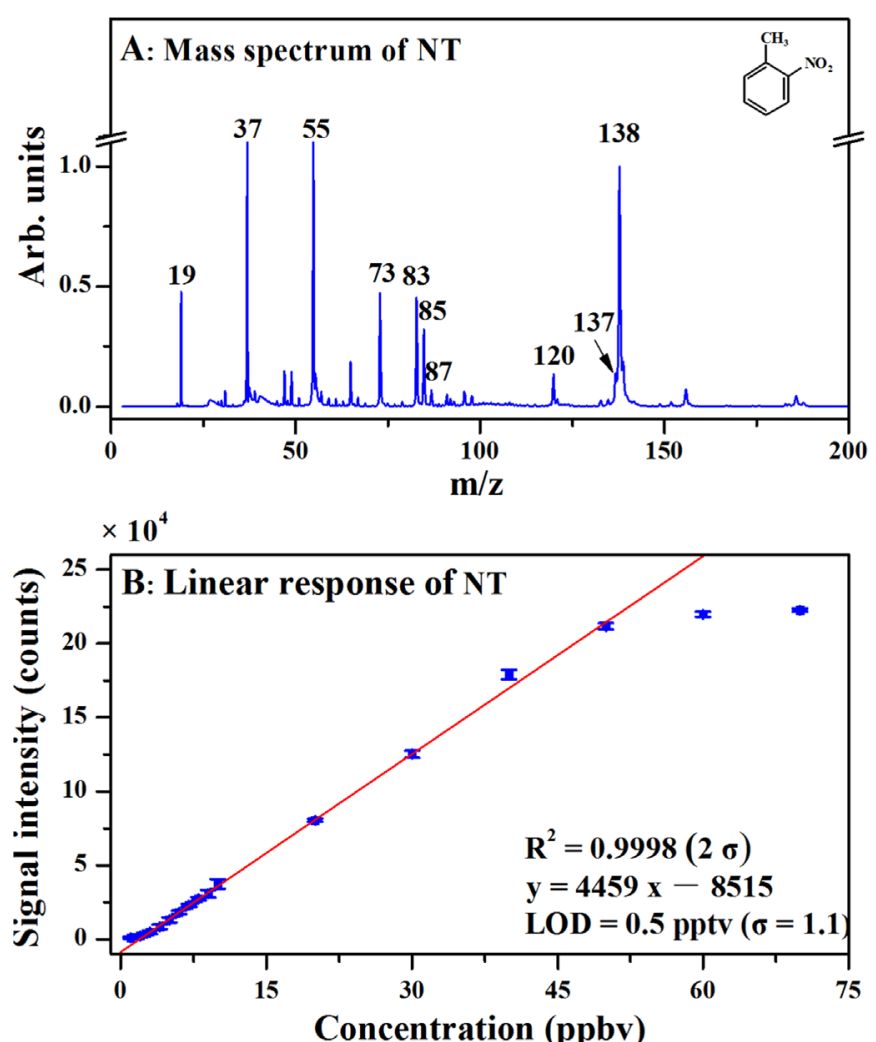

Fig. 3. Low-pressure photoionization mass spectrum (A) and linear response (B) of nitrotoluene (NT).

may have resulted from the unique photoionizer, which enhances fragmentation during or after PI [26]. The LOD at a signal-to-noise ratio of 2 was estimated by $\mathrm{LOD}=2 \sigma \mathrm{c} / \mathrm{h}$, [27] where $\sigma$ is the standard deviation of the noise, $\mathrm{c}$ is the sample concentration, and $\mathrm{h}$ is the ion signal intensity. The noise $(\sigma)$ for the mass peak at $m / z$ 165 was 2.2 (200 measurements; the measured background is shown in Fig. S1). The mass peak at $m / z 165$ was the base peak in the spectrum with an intensity of 24790 counts and was thus used as the $h$ value. Note that this spectrum was obtained for using a saturated vapor of 2,4-DNT and the concentration of 2,4-DNT (c) was 170 ppbv (298 K) [6]. The LOD of the instrument towards 2,4-DNT was ultimately calculated to be $30 \mathrm{pptv}$ (2.4 pg). In previous studies, the LOD of gas chromatography/ PI-MS towards 2,4DNT was $\sim 40 \mathrm{ppbv}(2 \sigma),[6]$ and the LOD of sole PI-MS towards 2,4-DNT was 40 ppbv $(3 \sigma)$ [22]. The LOD obtained using this technique was improved by 3 orders of magnitude as compared to
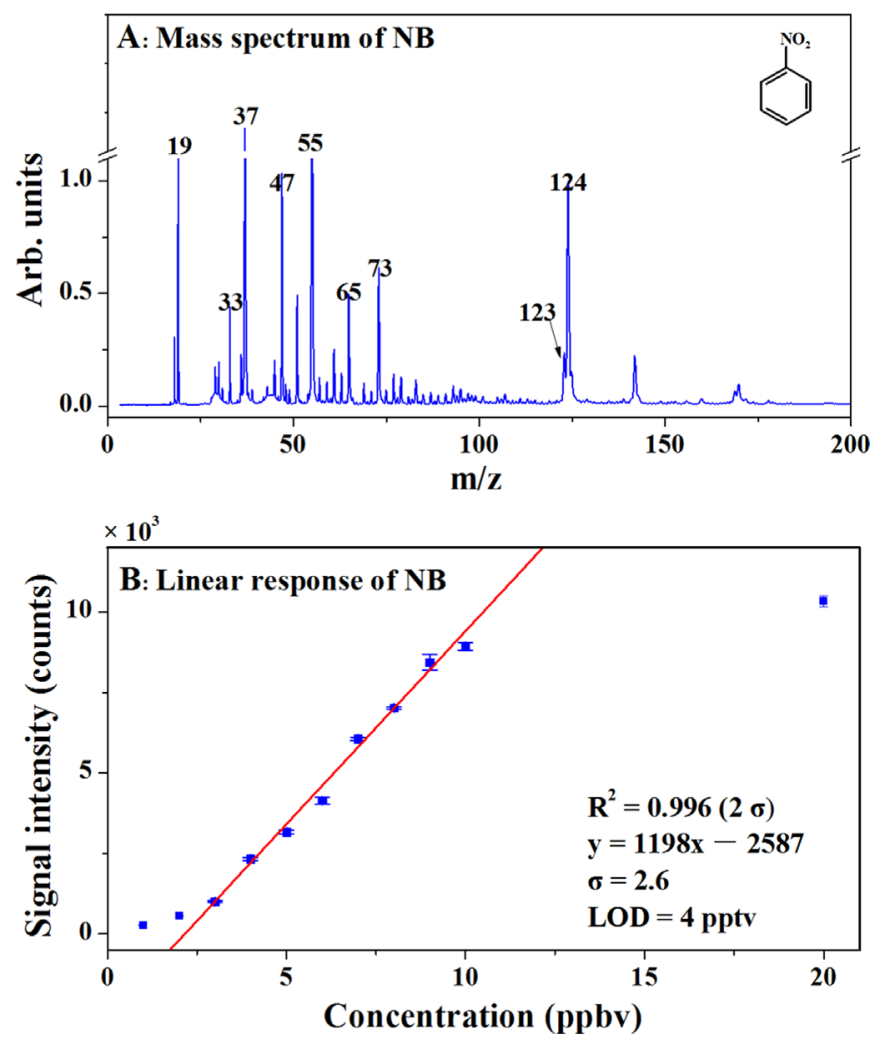

Fig. 4. Low-pressure photoionization mass spectrum (A) and linear response (B) of nitrobenzene (NB).
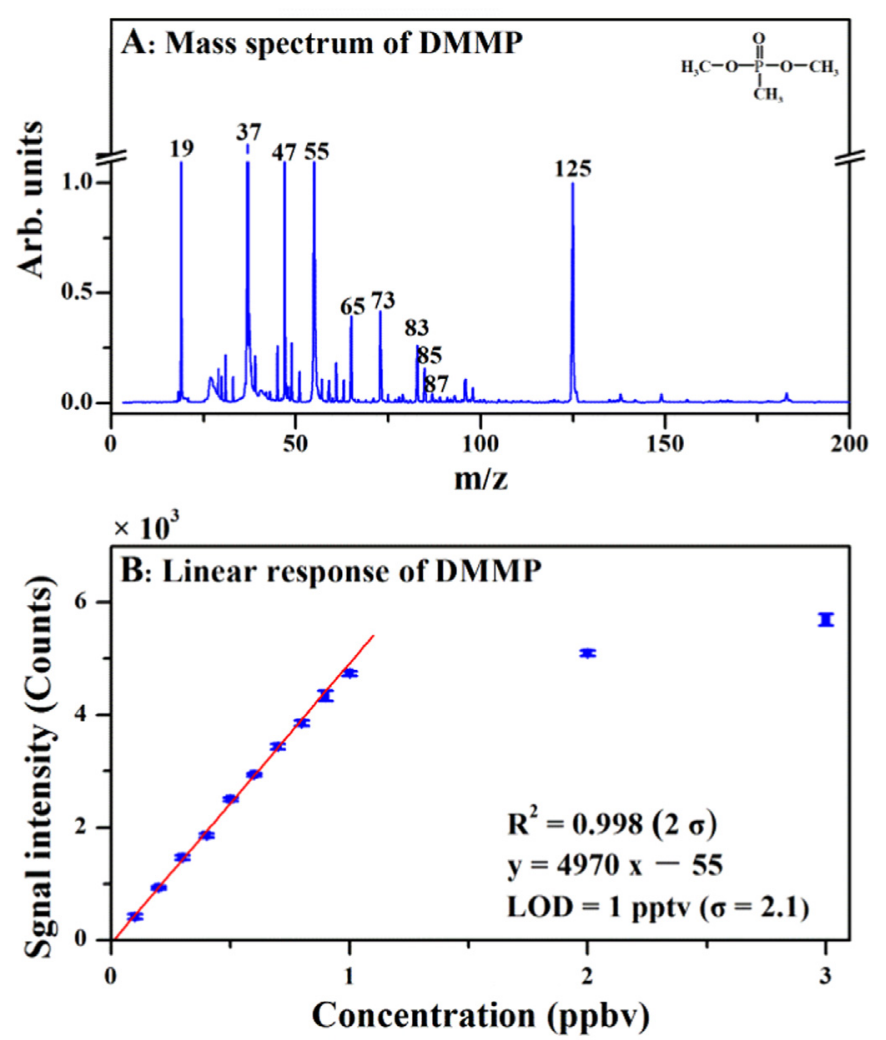

Fig. 5. Low-pressure photoionization mass spectrum (A) and linear response (B) of dimethyl methyl phosphonate (DMMP).

the previous reports. The repeatability of the 2,4-DNT signal at the low concentration (tens of ppbv) was very bad due to the severe absorption of the chamber wall, sample line, and valves. 
Table 1

LODs of selected TAs determined by PI-MS, IMS, PTR-MS and dog nose.

\begin{tabular}{|c|c|c|c|c|c|}
\hline \multirow[t]{2}{*}{ Number } & \multirow[t]{2}{*}{ Substance } & \multirow[t]{2}{*}{ Molecular weight } & \multicolumn{3}{|l|}{ LOD } \\
\hline & & & References & & This study $(2 \sigma)$ \\
\hline 1 & 2,4-DNT (2,4-dinitrotoluene) & 182 & $\begin{array}{l}\text { Gas chromatograph/ PI-MS: [6] } \\
\text { PI-MS: [22] }\end{array}$ & $\begin{array}{l}\sim 40 \operatorname{ppbv}(2 \sigma) \\
40 \operatorname{ppbv}(3 \sigma)\end{array}$ & 30 pptv, i.e., 2.4 pg \\
\hline 2 & NT (nitrotoluene) & 137 & - & - & 0.5 pptv, i.e., $0.03 \mathrm{pg}$ \\
\hline 3 & NB (nitrobenzene) & 123 & $\begin{array}{l}\text { Gas chromatograph/ PI-MS:[6] } \\
\text { PI-MS: [22] }\end{array}$ & $\begin{array}{l}17-24 \text { ppbv }(2 \sigma) \\
20 \text { ppbv }(3 \sigma)\end{array}$ & 4 pptv, i.e., 0.22 pg \\
\hline 4 & DMMP (dimethyl methyl Phosphonate) & 124 & $\begin{array}{l}\text { Thermal desorption- PI-MS: [20] } \\
\text { miniature PI-MS:[18] }\end{array}$ & $\begin{array}{l}750 \text { ng }(3 \sigma) \\
10-100 \text { ppbv }(3 \sigma)\end{array}$ & 1 pptv, i.e., 0.06 pg \\
\hline 5 & TAs & & IMS: [10] & $10 \mathrm{pptv}$ & $0.5-30$ pptv \\
\hline 6 & TAs & & PTR-MS: [13] & 2 pptv & $0.5-30$ pptv \\
\hline 7 & TAs & & Dog nose: [22] & $0.5-2$ ppbv & $0.5-30$ pptv \\
\hline
\end{tabular}

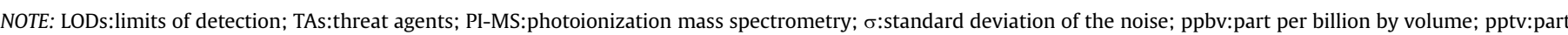
per trillion by volume.

Additionally, it is difficult for us to heat all the calibration system and the sample line in a uniform temperature now. Thus, the calibration curve was not given.

NT, a structural homolog of 2,4-DNT, was also detected using the proposed method. Fig. 3A shows the mass spectrum of NT. The mass peaks at 138 and 137 were assigned to the protonated NT and molecular ions of NT ( $\mathrm{IE}=9.24 \mathrm{eV})$, respectively. The mass peak at $\mathrm{m} / \mathrm{z} 120$ corresponded to $\mathrm{C}_{7} \mathrm{H}_{6} \mathrm{NO}$, a daughter ion of $\mathrm{NT}$, which was formed upon loss of $\mathrm{OH}$. Notably, the loss of $\mathrm{OH}$ from NT by PI-MS was reported previously [6]. The mass peaks at $m / z 19,37,55,73$, 83,85 , and 87 could not be assigned to daughter ions of NT. However, the first four peaks were assigned to protonated $\mathrm{H}_{2} \mathrm{O}$, $\left(\mathrm{H}_{2} \mathrm{O}\right)_{2},\left(\mathrm{H}_{2} \mathrm{O}\right)_{3}$, and $\left(\mathrm{H}_{2} \mathrm{O}\right)_{4}$, respectively. Protonated water and water clusters originate from the background gases in the chamber [26]. The others were assigned to organic residuals in the chamber. In comparison to the mass spectrum of 2,4-DNT, NT yielded fewer fragment ions. The mass spectrum of NT was dominated by protonated NT, while the intensity of the molecular ion peak was only $\sim 1 / 10$ of that of protonated NT. Thus, the linear response of NT shown in Fig. 3B was obtained based on the signal of the protonated ion. A satisfactory linear response $\left(R^{2}=0.9998\right)$ was obtained from 0 to $50 \mathrm{ppbv}$. The slope of the fitted line was 4459 counts/ppbv and the LOD was $0.5 \mathrm{pptv}(2 \sigma, \sigma=1.1)$, i.e., $0.03 \mathrm{pg}$. The linear fitting in Fig. 3B yielded a negative intercept of 8515 counts, which resulted from the absorption of the chamber to the sample. In the higher concentration range, signal saturation phenomenon exists (Fig. 3B). The accumulation of the high concentration solvent in the calibration chamber, which was used to dissolve the analytes, may partly lead to this phenomenon. By using an appropriate diluter with a fixed dilution ratio, the linear detection range of the instrument can be improved under the current condition.

Next, NB was detected using the proposed technique. Fig. 4A shows the mass spectrum of NB. The mass peak at $\mathrm{m} / \mathrm{z} 124$ was identified as the protonated form of NB and that at $m / z 123$ was assigned to the molecular ion of $\mathrm{NB}(\mathrm{IE}=9.94 \mathrm{eV})$. Fragment ions of NB were not found owing to the fact that the fragment formation occurs at no less than $10.9 \mathrm{eV}$ [28]. Apart from the protonated water and water clusters, the additional mass peaks at $m / z 33,47$, and 65 were assigned to protonated $\mathrm{CH}_{3} \mathrm{OH}, \mathrm{C}_{2} \mathrm{H}_{5} \mathrm{OH}$, and $\left(\mathrm{CH}_{3} \mathrm{OH}\right)_{2}$, respectively. Protonated $\mathrm{CH}_{3} \mathrm{OH}, \mathrm{C}_{2} \mathrm{H}_{5} \mathrm{OH}$, and $\left(\mathrm{CH}_{3} \mathrm{OH}\right)_{2}$ were attributed from the cleaning agent used to clean the chamber, absolute ethyl alcohol. The mass spectrum of NB was dominated by protonated $\mathrm{NB}$, while the intensity of the molecular ion peak was only $\sim 1 / 5$ of that of protonated NB. The linear response of NB was obtained using the signal corresponding to protonated NB. Fig. 4B shows the linear response of NB. The slope of the fitted line was 1198 counts/ppbv and the $\sigma$ was 2.6 . The LOD was 4 pptv
$(2 \sigma)$, i.e., $0.2 \mathrm{pg}$. In previous studies, the LOD of NB ranged from 17 to 24 ppbv $(2 \sigma)$ by GC/ PI-MS, [6] while the LOD was only 20 ppbv $(3 \sigma)$ by sole PI-MS [22]. The LOD was improved by 4 orders of magnitude using the present technique as compared to the two methods abovementioned.

DMMP, a non-toxic substitute with structural similarities to the chemical warfare agent sarin, was also detected using the proposed technique. The mass spectrum for DMMP is displayed in Fig. 5A. The mass peak at $m / z 125$ corresponded to protonated DMMP. No molecular ion peak of DMMP was detected in this experiment, which might be due to its high proton affinity. Using thermal desorption- PI-MS, mass peaks at $\mathrm{m} / \mathrm{z} 124$ and 125 were observed [20]. Other mass peaks in the spectrum were assigned to protonated water, water clusters, and residual solvent. The linear response of DMMP shown in Fig. 5B was acquired according to the intensity of the protonated DMMP. A satisfactory linear response was obtained $\left(\mathrm{R}^{2}=0.998\right)$. The LOD was calculated to be $1 \mathrm{pptv}$ $(2 \sigma, \sigma=2.1)$, i.e., $0.06 \mathrm{pg}$. In comparison with the detection of DMMP by thermal desorption- PI-MS (750 ng), [20] an improvement of 7 orders of magnitude was obtained here. Compared to miniature PI-MS (10-100 ppbv), [18] an improvement of 4 orders of magnitude was obtained using the developed method.

\section{Conclusion}

The performance of the instrument in the detection of selected TAs, including 2,4-DNT, NT, NB, and DMMP, was compared to those of PI-MSs, IMS, PTR-MS, and dog nose; the results are summarized in Table 1. Based on the results, LPPI is an ultrasensitive (pptv or sub-pptv) technique for the detection of TAs. An improvement of 3-4 orders of magnitudes in the sensitivity was achieved in the detection of TAs without any pre-concentration, as compared to that in previous studies. The LPPI technique is still in development and the mechanism responsible for ion formation is not very clear. However, this study indicates that LPPI will open new opportunities for the sensitive detection of explosives and chemical warfare agents.

\section{Acknowledgement}

This study was supported by the National Natural Science Foundation of China (Grant No. 21277155) and the Strategic Priority Research Program of the Chinese Academy of Sciences (XDB05040501). 


\section{Appendix A. Supporting information}

Supplementary data associated with this article can be found in the online version at http://dx.doi.org/10.1016/j.talanta.2016.05.025.

\section{References}

[1] R.G. Ewing, M.J. Waltman, D.A. Atkinson, J.W. Grate, P.J. Hotchkiss, TrAC: Trend Anal. Chem. 42 (2013) 35.

[2] T.F. Jenkins, D.C. Leggett, P.H. Miyares, M.E. Walsh, T.A. Ranney, J.H. Cragin, V. George, Talanta 54 (2001) 501.

[3] V. George, T. F. Jenkins, D. C. Leggett, J. H. Cragin, J. M. Phelan, J. C. Oxley and J. Pennington, Progress on determining the vapor signature of a buried land mine, AeroSense'99, 1999; International Society for Optics and Photonics, 1999, 258.

[4] K.J. Albert, D.R. Walt, Anal. Chem. 72 (2000) 1947.

[5] E. Schramm, F. Muehlberger, S. Mitschke, G. Reichardt, R. Schulte-Ladbeck, M. Puetz, R. Zimmermann, Appl. Spectrosc. 62 (2008) 238.

[6] C. Mullen, A. Irwin, B.V. Pond, D.L. Huestis, M.J. Coggiola, H. Oser, Anal. Chem 78 (2006) 3807.

[7] Y. Seto, M. Kanamori-Kataoka, K. Tsuge, I. Ohsawa, K. Matsushita, H. Sekiguchi, T. Itoi, K. Iura, Y. Sano, S. Yamashiro, Sens. Actuators B Chem. 108 (2005) 193.

[8] A.B. Kanu, P. Dwivedi, M. Tam, L. Matz, H.H. Hill, J. Mass Spectrom. 43 (2008) 1.

[9] R.G. Ewing, D.A. Atkinson, G.A. Eiceman, G.J. Ewing, Talanta 54 (2001) 515.

[10] I.A. Buryakov, J. Anal. Chem. 66 (2011) 674.

[11] P. Sulzer, F. Petersson, B. Agarwal, K.H. Becker, S. Jurschik, T.D. Mark, D. Perry, P. Watts, C.A. Mayhew, Anal. Chem. 84 (2012) 4161.
[12] H.H. Hill, G. Simpson, Field Anal. Chem. Techol. 1 (1997) 119.

[13] S. Jurschik, P. Sulzer, F. Petersson, C.A. Mayhew, A. Jordan, B. Agarwal, S. Haidacher, H. Seehauser, K. Becker, T.D. Mark, Anal. Bioanal. Chem. 398 (2010) 2813.

[14] A.M. Ellis, C.A. Mayhew, Proton Transfer Reaction Mass Spectrometry: Principles and Applications, John Wiley \& Sons, New York 2013, p. 311.

[15] R. González-Méndez, D.F. Reich, S.J. Mullock, C.A. Corlett, C.A. Mayhew, Int. J. Mass Spectrom. 385 (2015) 13.

[16] J.A. Syage, B.J. Nies, M.D. Evans, K.A. Hanold, J. Am. Soc. Mass Spectrom. 12 (2001) 648.

[17] L. Hanley, R. Zimmermann, Anal. Chem. 81 (2009) 4174.

[18] J.A. Syage, M.A. Hanning-Lee, K.A. Hanold, Field Anal. Chem. Technol. 4 (2000) 204.

[19] R. Zimmermann, Anal. Bioanal. Chem. 405 (2013) 6901.

[20] E. Schramm, A. Kürten, J. Hölzer, S. Mitschke, F. Mühlberger, M. Sklorz, J. Wieser, A. Ulrich, M. Pütz, R. Schulte-Ladbeck, Anal. Chem. 81 (2009) 4456.

[21] E. Schramm, J. Hölzer, M. Pütz, R. Schulte-Ladbeck, R. Schultze, M. Sklorz, A. Ulrich, J. Wieser, R. Zimmermann, Anal. Bioanal. Chem. 395 (2009) 1795.

[22] B. Pond, C. Mullen, I. Suarez, J. Kessler, K. Briggs, S. Young, M. Coggiola, D. Crosley, H. Oser, Appl. Phys. B 86 (2007) 735.

[23] 〈http://www.waters.com/waters/en_US/APPI-APCI-Dual-Mode-IonizationSource/nav.htm?cid $=1000390$ \&lset $=1$ \&locale $=$ en_US\&changedCountry $=Y\rangle$. [24] J.A. Syage, J. Am. Soc. Mass Spectrom. 15 (2004) 1521.

[25] C. Liu, Y. Zhu, Z. Zhou, J. Yang, F. Qi, Y. Pan, Anal. Chim. Acta 891 (2015) 203.

[26] W.Q. Sun, J.N. Shu, P. Zhang, Z. Li, N.N. Li, M. Liang, B. Yang, Atmos. Meas. Tech. 8 (2015) 4637.

[27] F. Muhlberger, R. Zimmermann, A. Kettrup, Anal. Chem. 73 (2001) 3590.

[28] L. Cooper, L.G. Shpinkova, E.E. Rennie, D.M.P. Holland, D.A. Shaw, Int. J. Mass Spectrom. 207 (2001) 223. 